\title{
Seasonality and Regionality of the Madden-Julian Oscillation and Convectively Coupled Equatorial Waves
}

\author{
Kazuaki Yasunaga \\ Research Institute for Global Change, Japan Agency for Marine-Earth Science and Technology (RIGC/JAMSTEC), \\ Yokosuka, Japan
}

\begin{abstract}
This study examines seasonal and regional variations in the amplitudes of convectively coupled equatorial waves (CCEWs), including Madden-Julian oscillation (MJO) and tropical depression (TD) disturbances. The climatological seasonal variations of the $n=1$ equatorial Rossby (ERn1) wave are similar to those of the MJO over the Indian Ocean and the central Pacific. The antisymmetric components of CCEWs (mixed Rossby gravity, $n$ $=0$ eastward inertial gravity, and $n=2$ westward inertial gravity waves; MRG, EIGn0, and WIGn2 waves, respectively) show similar seasonal cycles over the central Pacific with peaks during boreal summer and fall.

CCEW amplitudes are also examined as a function of the MJO phase. The activities of all CCEWs except for the MRG wave are significantly enhanced in the convectively mature phase of the MJO over the Indian Ocean, whereas the amplitude peak of the Kelvin and WIGn1 (ERn1 and TD) waves shifts from the mature phase over the Indian Ocean to the convectively developing (decaying) phase of the MJO over the western and central Pacific. The MRG wave has an amplitude maximum in the decaying phase over the Indian Ocean, and the peak shifts to the preceding phase of the MJO over the Pacific Ocean.
\end{abstract}

\section{Introduction}

Temporal variations in tropical convection occur on various scales ranging from hours to seasons and beyond. The MaddenJulian oscillation (MJO: Madden and Julian 1971, 1972) is one of the most prominent phenomena regulating tropical convection. A significant correspondence between the zonal wavenumberfrequency spectra of the cloud field and the dispersion relationships of linear equatorial waves (Matsuno 1966) clarifies that convectively coupled equatorial waves (CCEWs) are also crucial in controlling tropical convection (e.g., Takayabu 1994; Wheeler and Kiladis 1999). On the other hand, many questions on CCEWs, including the MJO, remain unexplained, for example, the generation mechanisms preferred mode types, wavenumbers, and frequencies.

The MJO shows strong seasonality and regionality. Its activity normally peaks spatially over the warm pool of the Indian and western Pacific oceans [or regions with a high sea-surface temperature (SST)] and peaks seasonally in boreal winter (Madden 1986; Gutzler and Madden 1989; Salby and Hendon 1994; Zhang and Dong 2004). Seasonality and regionality are also reported for some CCEWs (e.g., Suzuki and Shiotani 2008; Hendon and Liebmann 1991; Wheeler and Kiladis 1999). However, comprehensive investigations of seasonal and regional activities of CCEWs including the $\mathrm{MJO}$, in which a single approach is applied to the same data, have not been attempted. Therefore, a close examination of their seasonality and regionality is expected to improve our knowledge of the MJO and CCEWs.

Cumulus parameterization has been recognized as one of the

Corresponding author: Kazuaki Yasunaga, RIGC/JAMSTEC, 2-15 Natsushima-Cho, Yokosuka-city, Kanagawa 237-0061, Japan. E-mail: yasunaga @jamstec.go.jp. C2011, the Meteorological Society of Japan.

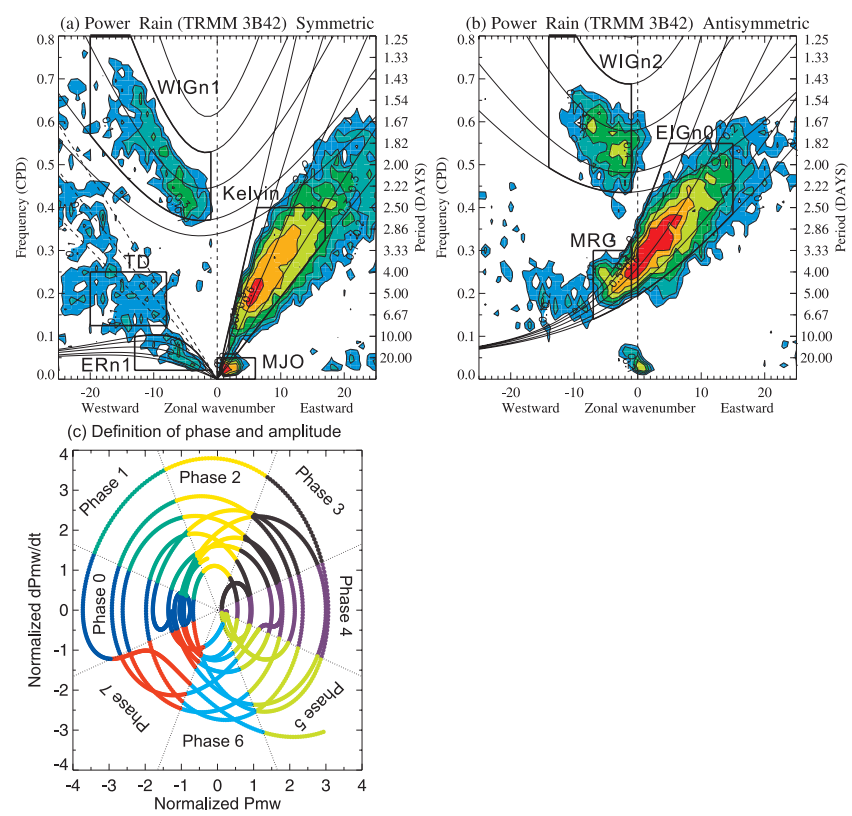

Fig. 1. Signal strength of symmetric (a) and antisymmetric (b) components of precipitation (TRMM-3B42) over $15^{\circ} \mathrm{S}-15^{\circ} \mathrm{N}$. The shading interval is 0.1 with the first level at 0.1 . Positive and negative wavenumbers correspond to eastward and westward propagation, respectively. Dispersion curves are also plotted for the Kelvin, $n=1$ equatorial Rossby (ERn1), $n$ $=1$ and $n=2$ westward inertial gravity (WIGn1, WIGn2), $n=0$ eastward inertial gravity (EIGn0), and mixed Rossby-gravity (MRG) waves with equivalent depths of $8,12,25,50$, and $90 \mathrm{~m}$, respectively. Three dashed lines representing the symmetric components indicate constant phase speeds of 7.0, 9.0, and $11.0 \mathrm{~m} \mathrm{~s}^{-1}$. Regions enclosed with heavy solid lines represent filters for the isolation of each wave's activity. (c) Phase portrait using the time series of MJO-filtered precipitation (abscissa) and its time derivative (ordinate) along the longitude of $120^{\circ} \mathrm{E}$ from $01 \mathrm{Jan} .2008$ to 01 Jan. 2009. Eight phases are indicated with different colors.

most uncertain aspects of a global climate model. Lin et al. (2006) evaluated the fidelity of CCEWs in climate models by focusing on the spectral peaks of precipitation and noted that CCEWs and MJO are inconsistently simulated by models with parameterized convection. The vertical structure and evolutions of CCEWs have also been explored, revealing several shortcomings in simulated CCEWs (e.g., Straub et al. 2010). The present study provides further observational benchmark for validating MJO and CCEW simulations.

Several hypotheses describe CCEWs in the MJO as a key to understanding it (e.g., Wang and Rui 1990; Masunaga et al. 2006; Masunaga 2007; Kikuchi and Wang 2010). If a particular CCEW is essential to the MJO, its activity is expected to be closely related to that of the MJO. Straub and Kiladis (2003) indicated that mixed Rossby gravity (MRG) wave activity is enhanced within the boreal summer intraseasonal oscillation (ISO) envelope during its convectively active phase, and that Kelvin wave activity is also enhanced to the east of the active ISO convection, in the central Pacific. Yasunaga and Mapes (2011) comprehensively examined 


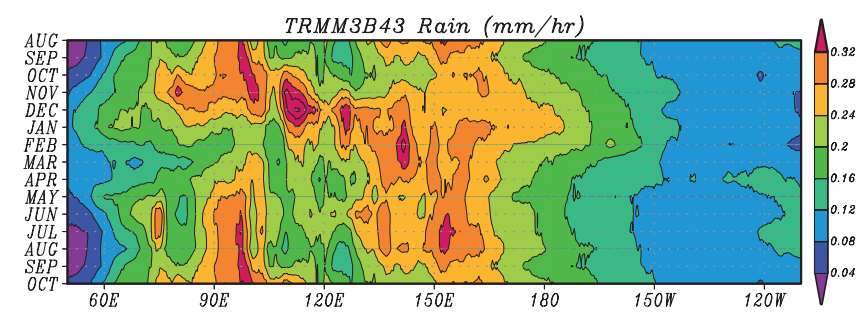

Fig. 2. Seasonal and longitudinal variations in the total rainfall (TRMM3B42) over $15^{\circ} \mathrm{S}-15^{\circ} \mathrm{N}$.

the modulation of the CCEW amplitudes by the MJO amplitude and phase over the warm pool $\left(60^{\circ} \mathrm{E}-180^{\circ} \mathrm{EW}\right)$. The activity of all CCEWs is significantly enhanced and inhibited during convectively active and suppressed phases of the MJO, respectively (Figs. $12 \mathrm{c}$ and $12 \mathrm{~d}$ of Yasunaga and Mapes 2011). However, the regional variations they report are unclear. Therefore, the present study further explores the regionality of the modulation in the CCEW activity associated with the MJO phase.

The remainder of this paper is organized as follows. In Section 2 , the data and analysis procedure used are briefly described; the power spectra of rain are also shown. In Section 3, the seasonal and geographical variations in the MJO and CCEW activity are presented, along with the climatological annual cycle of rainfall. Correlations between MJO rainfall anomalies and CCEW amplitudes are also shown in Section 3. The results are summarized in Section 4.

\section{Data and methodology}

In this study, TRMM-3B42 data were used. TRMM-3B42 (version 6) provides precipitation distributions in a global belt extending from $50^{\circ} \mathrm{S}$ to $50^{\circ} \mathrm{N}$ from 1998 to the present, with a $3 \mathrm{~h}$ temporal resolution and a $0.25^{\circ} \times 0.25^{\circ}$ spatial resolution. Huffman et al. (2007) provided a more detailed description of the product.

We analyzed 13 years of records (1998-2010) over the equatorial band $\left(15^{\circ} \mathrm{S}-15^{\circ} \mathrm{N}\right)$ and isolated CCEW precipitation signals in the longitude-time domain by filtering precipitation anomalies in the wavenumber-frequency domain. The precipitation anomalies were obtained by subtracting the mean and the first three annual harmonics and decomposing the remainder into the equatorially symmetric and antisymmetric components of the $15^{\circ} \mathrm{N}-15^{\circ} \mathrm{S}$ equatorial belt. Figure 1 shows the signal strength, which is defined as the fraction of the total power that stands above the background (see Hendon and Wheeler 2008) in the symmetric and antisymmetric power spectra of precipitation in the frequency-wavenumber domain. We defined filters for CCEWs as the regions enclosing the peaks in Fig. 1 (ERn1: $n=1$ equatorial Rossby wave, Kelvin: Kelvin wave, WIGn1: $n=1$ westward inertial gravity wave, MRG: mixed Rossby-gravity wave, EIGn0: $n=0$ eastward inertial gravity wave, WIGn2: $n=2$ westward inertial gravity wave). The filters generally agree with those used in previous investigations (e.g., Kiladis et al. 2009; Wheeler and Kiladis 1999). Note that precipitation associated with MJO and tropical depression (TD) disturbances was also isolated using the same filtering technique.

The phase and amplitude for each CCEW type were calculated from the filtered precipitation time-longitude section and its time derivative. Both quantities (filtered precipitation anomaly and its time derivative) were normalized by the standard deviations of the entire time-longitude sections (for all years, seasons, and global longitudes). We define the wave phase and amplitude as the arctangent (angle) and squared sum (distance from origin), respectively, of the two variables (e.g., Fig. 1c). Further details of the procedures are described in Yasunaga and Mapes (2011).
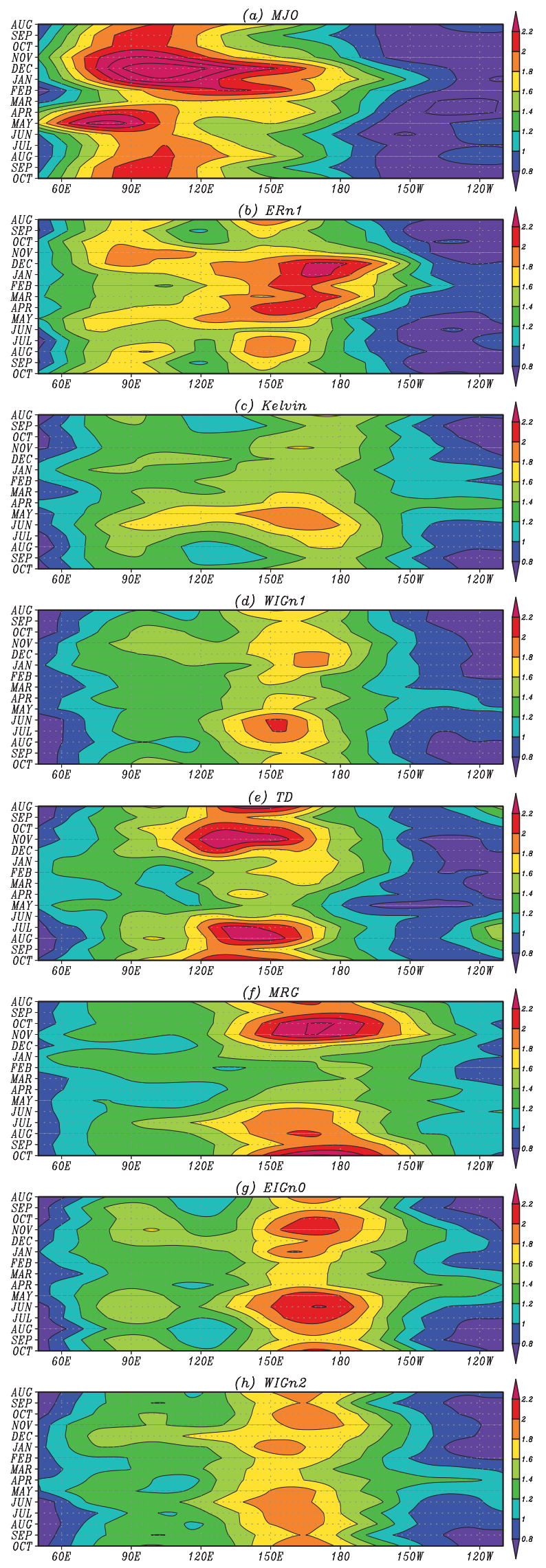

Fig. 3. Seasonal and longitudinal variations in the amplitude of CCEWs (ERn1, Kelvin, WIGn1, MRG, EIGn0, and WIGn2 waves), including MJO and TD disturbances. 


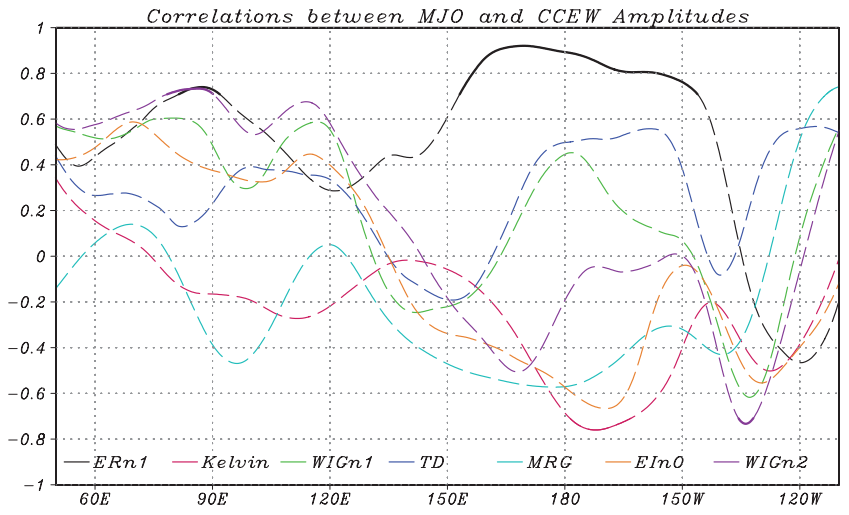

Fig. 4. Correlations between seasonal variations in the MJO and CCEW amplitudes (Fig. 3) at each longitude. Thick solid lines indicate significant correlation at the $99 \%$ level.

\section{Results and discussion}

Figure 2 shows the seasonal and geographical variations in total rainfall. The rainfall amounts are largest over the Indian Ocean and the central Pacific (around $150^{\circ} \mathrm{E}-180^{\circ} \mathrm{E}$ ); the precipitation shows a clear seasonal progression, which starts in the Indian Ocean in boreal fall and ends in the western Pacific (around $120^{\circ} \mathrm{E}-150^{\circ} \mathrm{E}$ ) in boreal winter. Meehl (1987) first reported this seasonal progression. Figure 3 shows the seasonal and longitudinal variations in the monthly mean amplitude of CCEWs, including the MJO and TD disturbances. Variations in MJO are most prominent over the Indian Ocean, whereas for CCEWs (the ERn1, Kelvin, WIGn1, MRG, EIGn0, and WIGn2 waves), the most active area appears in the central Pacific. In contrast, the TD amplitudes are larger over the western Pacific. These geographical features are consistent with the results obtained by Wheeler and Kiladis (1999) and Wheeler et al. (2000), although they used different data.

The MJO activity peaks seasonally during boreal winter (November, December, January, and February) and spring (April and May), which is also consistent with a previous study (Zhang and Dong 2004). MJO activity shifts to the central Pacific in boreal winter, whereas the spring peak is confined over the Indian Ocean. The ERn1 wave shows seasonal patterns similar to those of the MJO, especially over the Indian Ocean and the central Pacific. On the other hand, the Kelvin wave is most active during May and June, when precipitable water reaches a peak over the Indian Ocean and the central Pacific (not shown). The WIGn1 wave has two seasonal peaks during boreal summer and winter, respectively, over the central Pacific. The antisymmetric components of CCEWs (MRG, EIGn0, and WIGn2 waves) show similar seasonal cycles over the central Pacific with peaks during boreal summer and fall, although the seasonal variations in WIGn2 are subtle. Hendon and Liebmann (1991) attributed the generation of the MRG wave during boreal fall to the unique SST distribution (equatorial minimum flanked by maxima at about $5-10^{\circ}$ latitude). A similar seasonality among the MRG, EIGn0, and WIGn2 waves suggests that such SST distributions are essential to all antisymmetric CCEW components. The TD seasonal cycle also resembles those of the antisymmetric components, although the longitudinal peaks are shifted to the west. Previous studies have reported a close relationship between the MRG wave and TD disturbances (e.g., Takayabu and Nitta 1993).

To objectively evaluate the similarity in the seasonal cycles of the MJO and CCEW amplitudes, we calculated the correlation coefficients between the amplitudes using the climatological seasonal variations shown in Fig. 3. ERn1 shows the most significant correlation with the MJO over the Indian Ocean and the central Pacific (Fig. 4). The WIGn2 wave is also highly correlated with the MJO over the Indian Ocean, although the range of seasonal (a) Activity of Wave (Symmetric)

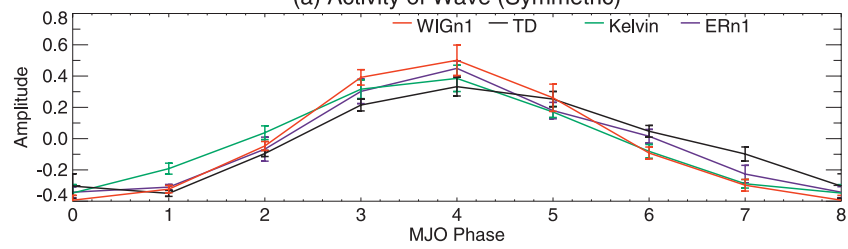

(b) Activity of Wave (Antisymmetric)

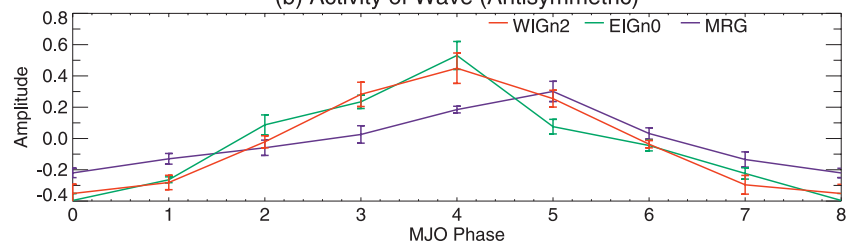

Fig. 5. Composite mean amplitude of CCEWs at each MJO phase for symmetric (a) and antisymmetric (b) components over the Indian Ocean $\left(60^{\circ} \mathrm{E}-90^{\circ} \mathrm{E}\right)$. Amplitude of CCEWs is determined by wave-filtered rainfall (TRMM-3B42) and its derivative (see the text). To calculate the mean, data having an MJO amplitude larger than 2.0 are used. Error bars indicate $90 \%$ significance range. Mean value over the MJO phase is subtracted for easy comparison.

variation is small (Fig. 3h). Moreover, the Kelvin wave and the $\mathrm{MJO}$ are negatively correlated over the central Pacific.

The most significant correlations between the MJO and the ERn1 wave appeared over the central Pacific, even when time-series wave amplitude data with a $3 \mathrm{~h}$ interval were used instead of the climatological seasonal variations (not shown). These results suggest that common external factors affect MJO and ERn1 wave activity over the Indian Ocean and the central Pacific, where an MJO convective envelop breaks out and collapses, respectively.

Next, modulation of the CCEW amplitudes by the MJO phase over the Indian Ocean $\left(60^{\circ} \mathrm{E}-90^{\circ} \mathrm{E}\right)$ was compared with that over the western and central Pacific $\left(120^{\circ} \mathrm{E}-180^{\circ} \mathrm{EW}\right)$ to clarify the regionality of the relationships between the MJO and CCEWs (Figs. 5 and 6). Eight $45^{\circ}$ phase angle wedges (as in Fig. 1c) and 41 amplitude bins of 0.1 standard deviation width were chosen as the discrete phase and amplitude bins, respectively, of the MJO. To calculate the mean activity, composites of the CCEW amplitude were built for these eight phases and 41 amplitudes (0-4.0 with 0.1 bins), and the composite amplitudes were averaged over the MJO amplitudes of 2.0-4.0 (21 samples) for each phase. More details are available in Yasunaga and Mapes (2011).

For the symmetric components of CCEWs, the peaks in the wave activity all appear in the convectively mature phase of the MJO (phase 4) over the Indian Ocean (Fig. 5a). However, the peak shifts to the convectively developing phase of the MJO (phase 3) over the western and central Pacific for Kelvin and WIGn1 waves, whereas the ERn1 and TD waves have an amplitude peak in the convectively decaying phase (phase 5) there (Fig. 6a). For the antisymmetric components, the EIGn0 and WIGn2 waves also show an amplitude maximum in the convectively mature phase over the Indian Ocean, whereas MRG wave activity is most enhanced in the convectively decaying phase there (Fig. 5b). However, the shift in the peak phase, which is found in the symmetric components, is obscure for the EIGn0 and WIGn2 waves (Fig. 6b). The amplitude maximum of the MRG wave shifts to the preceding phase of the MJO over the Pacific Ocean, although the peak phase is difficult to identify owing to the large error bars there (Fig. 6b).

\section{Summary}

The present study examined seasonal and regional variations in the MJO and CCEW amplitudes in order to seek clues about a common environmental factor controlling their activities. Using TRMM-3B42 precipitation datasets, the CCEW amplitudes were defined as the squared sum of the filtered precipitation anomaly 
(a) Activity of Wave (Symmetric)

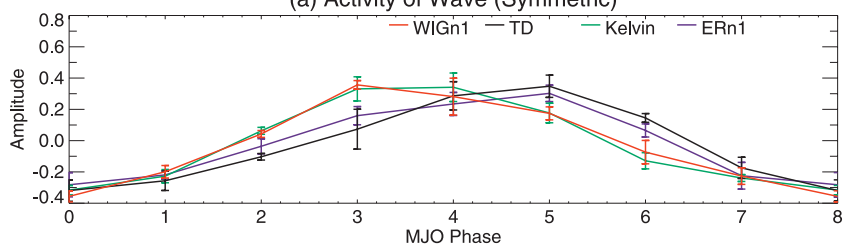

(b) Activity of Wave (Antisymmetric)

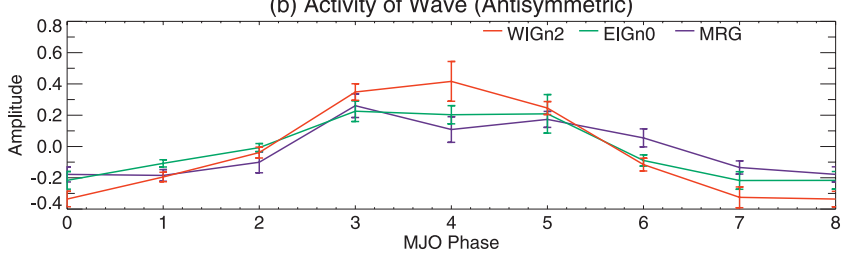

Fig. 6. Same as Fig. 5 except for composite mean amplitude of CCEWs over the western and central Pacific $\left(120^{\circ} \mathrm{E}-180^{\circ} \mathrm{EW}\right)$.

and its time derivative. The ERn1 wave and MJO showed similar seasonal cycles over the Indian Ocean and central Pacific. Similar seasonal variations were also found among the antisymmetric components of CCEWs (the MRG, EIGn0, and EIGn2 waves) over the central Pacific, with peaks during boreal summer and fall. A significant correlation between the MJO and the ERn1 wave was obtained when time sequential data with a $3 \mathrm{~h}$ interval as well as climatological monthly mean data. Therefore, it is likely that common environmental factors affect MJO and ERn1 wave activity over the Indian Ocean and central Pacific.

CCEW amplitudes were also examined as a function of MJO phase. The activity of all CCEWs except for the MRG wave are most enhanced in the convectively mature phase of the MJO over the Indian Ocean. Furthermore, the activity peak of the Kelvin and WIGn1 (ERn1 and TD) waves shifts to the MJO developing (decaying) phase over the western and central Pacific, whereas the shift in the peak phase is obscure for the EIGn0 and WIGn2 waves. The MRG wave exhibits an amplitude peak in the convectively decaying phase over the Indian Ocean and shifts to the preceding phase of the MJO over the Pacific Ocean.

\section{Acknowledgments}

The results in this study were obtained using the TRMM3B42 product. We express our sincere thanks to all concerned with supplying the product. Scientific discussions with Dr. Nishi and helpful comments from Dr. Kikuchi and an anonymous reviewer are gratefully acknowledged.

\section{References}

Gutzler, D. S., and R. A. Madden, 1989: Seasonal variations in the spatial structure of intraseasonal tropical wind fluctuations. $J$. Atmos. Sci., 46, 641-660.

Hendon, H. H., and B. Liebmann, 1991: The structure and annual variation of antisymmetric fluctuations of tropical convection and their association with Rossby-gravity waves. $J$. Atmos. Sci., 48, 2127-2140.

Hendon, H. H., and M. C. Wheeler, 2008: Some space-time spectral analyses of tropical convection and planetary-scale waves. J. Atmos. Sci., 65, 2936-2948.

Huffman, G. J., D. T. Bolvin, E. J. Nelkin, D. B. Wolff, R. F. Adler, G. Gu, Y. Hong, K. P. Bowman, and E. F. Stocker, 2007: The TRMM Multisatellite Precipitation Analysis (TMPA): Quasi-global, multiyear, combined-sensor precipitation estimates at fine scales. Journal of Hydrometeorology, $\mathbf{8}, 38-55$.
Kikuchi, K., and B. Wang, 2010: Spatiotemporal wavelet transform and the multiscale behavior of the Madden-Julian oscillation. J. Climate, 23, 3814-3834.

Kiladis, G. N., M. C. Wheeler, P. T. Haertel, K. H. Straub, and P. E. Roundy, 2009: Convectively coupled equatorial waves. Rev. Geophys., 47, RG2003, doi:10.1029/2008RG000266.

Lin, J.-L., G. N. Kiladis, B. E. Mapes, K. M. Weickmann, K. R. Sperber, W. Lin, M. C. Wheeler, S. D. Schubert, A. Del Genio, L. J. Donner, S. Emori, J.-F. Gueremy, F. Hourdin, P. J. Rasch, E. Roeckner, and J. F. Scinocca, 2006: Tropical intraseasonal variability in 14 IPCC AR4 climate models. Part I: Convective signals. J. Climate, 19, 2665-2690.

Madden, R. A., 1986: Seasonal variations of the 40-50 day oscillation in the tropics. J. Atmos. Sci., 43, 3138-3158.

Madden, R. A., and P. R. Julian, 1971: Detection of a 40-50 day oscillation in the zonal wind in the tropical Pacific. J. Atmos. Sci., 28, 702-708.

Madden, R. A., and P. R. Julian, 1972: Description of global-scale circulation cells in the tropics with a $40-50$ day period. $J$. Atmos. Sci., 29, 1109-1123.

Masunaga, H., 2007: Seasonality and regionality of the MaddenJulian oscillation, Kelvin wave, and equatorial Rossby wave. J. Atmos. Sci., 64, 4400-4416.

Masunaga, H., T. S. Ecuyer, and C. D. Kummerow, 2006: The Madden-Julian oscillation recorded in early observations from the Tropical Rainfall Measuring Mission (TRMM). $J$. Atmos. Sci., 63, 2777-2794.

Matsuno, T., 1966: Quasi-geostrophic motions in the equatorial area. J. Meteor. Soc. Japan, 44, 25-43.

Meehl, G. A., 1987: The annual cycle and interannual variability in the tropical Pacific and Indian Ocean regions. Mon. Wea. Rev., 115, 27-50.

Salby, M. L., and H. H. Hendon, 1994: Intraseasonal behavior of clouds, temperature, and motion in the tropics. J. Atmos. Sci., 51, 2207-2224.

Straub, K. H., and G. N. Kiladis, 2003: Interactions between the boreal summer intraseasonal oscillation and higherfrequency tropical wave activity. Mon. Wea. Rev., 131, 945960.

Straub, K. H., P. T. Haertel, and G. N. Kiladis, 2010: An analysis of convectively coupled Kelvin waves in 20 WCRP CMIP3 global coupled climate models. J. Climate, 23, 3031-3056.

Suzuki, J., and M. Shiotani, 2008: Space-time variability of equatorial Kelvin waves and intraseasonal oscillations around the tropical tropopause. J. Geophys. Res., 113, D16110, doi: 10.1029/2007JD009456.

Takayabu, Y. N., 1994: Large-scale cloud disturbances associated with equatorial waves. J. Meteor. Soc. Japan, 72, 433-449.

Takayabu, Y. N., and T. Nitta, 1993: 3-5 day-period disturbances coupled with convection over the tropical Pacific Ocean. $J$. Meteor. Soc. Japan, 71, 221-246.

Wang, B., and H. Rui, 1990: Dynamics of the coupled moist Kelvin-Rossby wave on an equatorial B-plane. J. Atmos. Sci., 47, 397-413.

Wheeler, M., and G. N. Kiladis, 1999: Convectively coupled equatorial waves: Analysis of clouds and temperature in the wavenumber-frequency domain. J. Atmos. Sci., 56, 374-399.

Wheeler, M., G. N. Kiladis, and P. J. Webster, 2000: Large-scale dynamical fields associated with convectively coupled equatorial waves. J. Atmos. Sci., 57, 613-640.

Yasunaga, K., and B. Mapes, 2011: Differences between moredivergent vs. more-rotational types of Convectively Coupled Equatorial Waves. Part II: Composite Analysis based on space-time filtering. J. Atmos. Sci., doi:10.1175/JAS-D-11034.1

Zhang, C., and M. Dong, 2004: Seasonality in the Madden-Julian oscillation. J. Climate, 17, 3169-3180.

Manuscript received 5 August 2011, accepted 16 September 2011 SOLA: http://www.jstage.jst.go.jp/browse/sola 